\title{
Profile of Descriptive Parameters of Pulmonary Function in Patients with Dyspnea
}

\author{
Kanmi Ningshen ${ }^{1}$,W.Kanan ${ }^{2}$,W.Asoka Singh ${ }^{3}$,AshemNandarani Devi ${ }^{4}$, \\ A Jannie Shimray ${ }^{5}$,Sharon Roel $^{6}$, G Majachunglu ${ }^{7}$,Hongprachan Hungyo ${ }^{8}$ \\ ${ }^{I}$ Physiology Dept, RIMS Imphal, ${ }^{2}$ Professor Physiology Dept RIMS Imphal \\ ${ }^{3}$ Prof and Head Respiratory Medicine Dept RIMS Imphal , ${ }^{4,5,6,7,8}$ PhysiologyDept, RIMS Imphal
}

\begin{abstract}
:
Background: Within any defined diseased group, the relationship between pulmonary function impairment and dyspnoea is reasonably close. This study was conducted to assess the relation of the different grades of dyspnoea to the pulmonary function and quantify breathlessness. Aim: This study was aimed to identify severity of dyspnoea and to establish a correlation with functional lung impairment. Methods: A cross-sectional study was conducted on 102 patients with complaints of dyspnoea, attending the outdoor department and indoor ward of respiratory medicine, RIMS Imphal. The patients were graded according to Modified Medical Research Council (MMRC) Dyspnoea Scale. Lung function test was performed by spirometry and Forced Vital capacity $(F V C)$, Forced Expiratory Volume in first second $\left(F E V_{l}\right), F E V_{1} / F V C$, Peak Expiratory Flow Rate (PEFR), Forced Expiration Flow rate ( $F E F_{25-75 \%}$ ) were studied. Result: There is a statistically significant reduction in $F V C, F E V_{1}, P E F R, F E F_{25-75 \%}$ as the grading of dyspnoea increases from grade 0 to grade IV. Conclusion: The deterioration in lung function parameters is directly related to the severity of dyspnoea as graded by MMRC dyspnoea scale. There is a strong correlation between the indirect (MMRC) and direct (spirometric values) evaluation of dyspnoea.
\end{abstract}

Keywords: dyspnoea, spirometry, Forced Vital capacity, FEV, PEFR, $F E F_{25-75 \%}$

\section{Introduction}

Dyspnoea is a clinical term for symptom of breathlessness ${ }^{[1]}$, with morbidityranging from mild annoyance to functional incapacitatation. This is usually associated with both electrocardiological abnormality and reduction in pulmonary function ${ }^{[2]}$. Dyspnoea can be caused by many conditions that increases respiratory work, reduce ventilatory capacity, and increased subjective sensitivity ${ }^{[3]}$. The predominant mechanism involves corollary discharge of respiratory motor activity and feedback from chemoreceptors and mechanoreceptors in the lung and chest wall. Behavioural style and emotional state also exerts an important influences on the expression of respiratory sensations ${ }^{[4]}$. A sudden onset of dyspnoea suggest pneumothorax(especially in young, otherwise healthy) or pulmonary embolism( in immobilized patients). A gradual development of dyspnoea indicates pulmonary infection, asthma, pulmonary oedema or neurological or muscular diseases ${ }^{[5]}$. Within any defined diseased group, the relationship between pulmonary functionimpairment and dyspnoea is reasonably close. However dyspnoea should be differentiated from tachypnea, hyperventilation and hyperpnea which refer to respiratory variations regardless of patient subjective sensation. These conditions may not always be associated with dyspnoea ${ }^{[6]}$. There has been a reported $10 \%$ to $18 \%$ prevalence of dyspnoea in population less than 65 years of age ${ }^{[7]}$. Mahler DA though stated that the reported prevalence of dyspnoea in different populations depends on the questionnaires used, smoking status, general activity level, geographic location, occupation and exposure to environmental pollution ${ }^{[8]}$. This study was conducted to assess the relation of the different grades of dyspnoea to the pulmonary function and quantify breathlessness.

\section{Methods:}

A total of 102subjects were involved in this study which included both the sexes of which 76 were males and 26 were females. Subjects between 18years and 75 years were considered for the study. Those patientsattending outpatient department and those admitted in the indoor ward of Respiratory MedicineDepartment,RIMSImphal were taken as subjects.Howeverdyspneic patients presenting with pneumothorax, TB, hypertension and those with cardiac diseases were also excluded from the study. The study was first approved by the Institutional Ethics Committee following which writtten informed consentwas taken from the subjects. The subjects were given the freedom to opt out of the study any time they wanted. The patients were then graded under Modified MedicalResearch Council(MMRC) dyspnea grading scale at the time of presentation as Grade 0 , I, II, III, IV. 
Grade 0 :breathlessness with strenuous exercise

Grade I : shortness of breath when hurrying or walking up a slight hill

Grade II: walk slower than people of same age on level ground or breathlessness when walking at own pace

Grade III: breathlessness after walking about 100 yards or after a few minutes on level ground

Grade IV: too breathless to leave the house or breathlessness on dressing.

All patients underwent a detailed history that included dyspnoea history, smokingstatus, occupation, chest pain, drug history and any associated conditions and physical examination.Blood pressure pulse rate were also measured. Pulmonary function test at the time of presentation was done by Helios 402 spirometer of Recorders and Medicare System, ChandigarhIndia.Forced Vital Capacity(FVC), Forced Expiratory Volume in first second $\left(\mathrm{FEV}_{1}\right), \mathrm{FEV}_{1} / \mathrm{FVC}$, Peak Expiratory Flow Rate(PEFR) and Flow Expiratory Rate $\left(\mathrm{FEF}_{25-75 \%}\right.$ ) were then recorded for each of the subjects. The study was conducted in the Department of Physiology, RIMS Imphal in association with the Department of Respiratory Medicine, RIMS, Imphal.

\section{Data analysis}

Dataare expressed as means \pm standard errors of the mean. The data were analysed by SSPS version 16 , one way ANOVA was used and $\mathrm{p}$ value $<0.005$ taken as statistically significant .

\section{Results}

Of the 102dyspneicpatients enrolled, 25subjects were found to be graded under MMRC grade 0 .grade I, grade II , grade III and grade IV included 30,28,12 and 9 patients respectively. $93 \%$ of Grade III and grade IVsubjects represented the indoor ward,while all of grade 0 and grade I were subjects from outpatient dept. $90 \%$ of MMRC grade II were a contribution of patients from outpatient department. While most of the subjects were found to be chronic dyspnoea cases, $19 \%$ presented as acute dyspnoea while the remaining were chronic cases of dyspnoea. Subjects under MMRC grade 0 comprised $80 \%$ by acute dyspnoea cases as in blunt, injury of chest, hysteria, acute gastritis and unidentified causes yet with no cardiological conditions. The other $20 \%$ was contributed by those patients of COPD on regular check- up. FEV Fhows $_{1}$ significant decline of \%predicted value from $87.7 \pm 2.76$ in grade 0 to $34.33 \pm 2.07$ in grade IV. PEFR also featured a \%predicted decline value with $62.6 \pm 2.97$ at grade 0 to $16.07 \pm 1.23$ in grade IV. Both $\mathrm{FEV}_{1} / \mathrm{FVC}$ and $\mathrm{FEF}_{25-75 \%}$ showed a similar pattern of decreasing value of \%predicted from grade I to grade IV, while grade 0 and grade I showed similar value. However FVC values of grade III and IV showed no significant changes (table I). $\mathrm{FEV}_{1} / \mathrm{FVC}$ \%predicted values for grade 0, I, II, II, IV were seen to be $108.8 \pm 1.74, \quad 116.46 \pm 1.29$, $101.38 \pm 2.9,95.33 \pm 2.63,77.56 \pm 3.14$ respectively.

Table I.descriptive parameters of spirometry (in \%predicted) grouped under MMRC dyspnoea scale Further evaluation of the above table by one way ANOVA, highlighted There is a statistically significant reduction in $\mathrm{FVC}, \mathrm{FEV}_{1}, \mathrm{PEFR}, \mathrm{FEF}_{25-75 \%}$ as the grading of dyspnoea increases from grade 0 to grade IV.

\begin{tabular}{|c|c|c|c|c|c|}
\hline & $\begin{array}{l}\text { FVC } \\
\quad \pm \text { S.D } \\
\end{array}$ & $\begin{array}{r}\mathrm{FEV}_{1} \\
\quad \pm \mathrm{S} . \mathrm{D} \\
\end{array}$ & $\begin{array}{c}\mathrm{FEV}_{1} / \mathrm{FVC} \\
\pm \mathrm{S} . \mathrm{D} \\
\end{array}$ & $\begin{array}{l}\text { PEFR } \\
\quad \pm \text { S.D } \\
\end{array}$ & $\begin{array}{r}\mathrm{FEF}_{25-75 \%} \\
\pm \mathrm{S} . \mathrm{D} \\
\end{array}$ \\
\hline $\begin{array}{lll}\text { MMRC } \quad 0 & \end{array}$ & $74.8 \pm 2.02$ & $82.7 \pm 2.76$ & $108.8 \pm 1.74$ & $62.6 \pm 2.97$ & $78.3 \pm 3.7$ \\
\hline MMRC 1 & $66.61 \pm 2.27$ & $79.07 \pm 3.11$ & $116.46 \pm 1.29$ & $60.23 \pm 2.5$ & $79.61 \pm 4.10$ \\
\hline MMRC 2 & $45.84 \pm 2.77$ & $50.69 \pm 3.68$ & $101.38 \pm 2.94$ & $33.69 \pm 3.12$ & $59.61 \pm 5.38$ \\
\hline MMRC 3 & $38.16 \pm 2.01$ & $35.16 \pm 2.04$ & $95.33 \pm 2.63$ & $17.83 \pm 1.48$ & $25.16 \pm 2.25$ \\
\hline MMRC 4 & $40.66 \pm 2.02$ & $36.33 \pm 2.07$ & $77.56 \pm 3.14$ & $17.07 \pm 1.24$ & $20 \pm 1.67$ \\
\hline
\end{tabular}

Table II. One way ANOVA between the different grades of MMRC against the spirometric parameters.

\begin{tabular}{|l|l|l|l|l|l|}
\hline & FVC & FEV1 & FEV $_{1} /$ FVC & PEFR & FEF $_{25-75 \%}$ \\
\hline P value & 0.002 & 0.001 & 0.009 & 0.000 & 0.003 \\
\hline
\end{tabular}

\section{Discussion}

The severity of dyspnea was the criteria for grading and grouping subjects, based on Modified Medical Research Council dyspnea scale. Spirometrywas done to assess the functional lung parameters. Our study found that the values of spirometric parameters decreased with the increased in the severity of dyspnea.A study by Lay $\mathrm{R}^{[9]}$ presented a discussion of pulmonary function and panic attacks in the context of respiratory psychosociology and concluded that the severity of dyspnea was a consequence of pulmonary function. NK Burki[5] mentioned that a sudden onset of dyspnoea suggest pneumothorax(in young, otherwise healthy) or 
pulmonary embolism(in immobilized patient). However in our study pneumothorax was excluded and acute dyspnoea was attributed more of towards blunt trauma of chest, after physical exercise, hysteria, acute gastritis and other unexplained cases but with no cardiologicalconditions. Spirometric parameters recorded in all the acute cases were found to be within normal limit except for 2 of 18 subjects of acute dyspnoea.

Grade 0 subjects were found having dyspnea despite no pulmonary conditions and the spirometric parameters were within normal limits while functional lung impairment were seen in all the other grades of dyspnea. Depaso WJ et al. ${ }^{[10]}$ described the spectrum and frequency of diseases presenting as unexplained dyspnea and pointed out that only $36 \%$ of the subjected patients were having dyspnea due to pulmonary disease.

We found that the $\mathrm{FEV}_{1} / \mathrm{FVC}$ ratio which serves as an important criteria to the diagnosis of obstructive lung disease showed values of $\%$ predicted $108.8 \pm 1.74,116.46 \pm 1.29,101.38 \pm 2.94,95.33 \pm 2.63,77.56 \pm 3.14$ for the different grades of MMRC scale, indicating statistically the closer relation of restrictive lung diseases to dyspnea. A study done by Wolkove $\mathrm{N}$ et al. ${ }^{[11]}$ on 93 patients with obstructive lung diseases included the measurement of breathlessness at rest using Borg Scale Dyspneic Index (BSDI) concluded that dyspnea is poorly correlated with results of routine spirometry in patients with obstructive lung diseases and suggested the use of dyspnea ratings may yield about bronchodilator responsiveness not appreciated by spirometry alone.

Delclaux C et al. ${ }^{[12]}$ studied 49 patients of sickle cell disease and made them underwent direct evaluations (Borg scale evaluation during a six minutes walk test) and indirect evaluations(MMRC dyspnoea score ) for their dyspnoea. Pulmonary function test (spirometry, Dlco and pulmonary capillary blood volume measurements), echocardiography and biological evaluations were done. The statistical analysis demonstrated that dyspnea and exercise performance were closely linked to indexes of Dlco. Another study by Bauer TT et al. ${ }^{[13]}$ also concluded that dyspnoea was approximated by Dlco. Their study was conducted on dyspneic subjects and investigated with High Resolution Computed Tomography, Pulmonary Function Test by spirometry and Dlcomeasurement.HoweverOur study shows a strong negative correlation between the indirect(MMRC) score and direct(spirometric values) evaluation of dyspnea as evident by the figures that the value of spirometric lung parameters declines rapidly as the severity of dyspnoea increases evaluated on MMRC scale.Grading of spirometry according to the complaints of the subjects however may lead to incorrect grading of MMRC since dyspnea may vary with time with exposure of aggravating factors, the influence of drugs that served to relieve dyspnoea. On the other hand the procedure of spirometry may also aggravated the symptom

\section{Conclusion:}

The deterioration in lung function parameters is directly related to the severity of dyspnoea as graded by MMRC dyspnoea scale. There is a strong correlation between the indirect (MMRC) and direct (spirometric values) evaluation of dyspnoea.

\section{References:}

[1]. StulbergMS,Adams L. Manisfestation of Respiratory disease : Dyspnea. In : Murray JR, Mason RJ, BoushayJr HA, Nadel JA, editors. Textbook of Respiratory Medicine, $3^{\text {rd }}$ Ed. Philadelphia : WB Saunders Company 2000; p.541-52.

[2]. Tessier JF, Nejjari C, Letennuer L, Filluel M, Mraty P, Gateau B, Dartigeus JF. Dyspnea and 8 year old mortality among elderly men and women : the PIQUID cohort study. Eur J Epidemiol 2001; 17:223-29.

[3]. Paula M, Schwartzstein RM, Adams L, Altose MD, Murray D, Bresli EA et al. Dyspnea : mechanism, assessment and management; A consensus statement. Am J Respir 1999;159:321-40.

[4]. Freedman S, Lane R, Guz A. Breathlessness and respiratory mechanism during reflex and voluntary hyperventilation in patients with chronic airflow limitation. ClinSci 1987;73:311-18.

[5]. NK Burki. Acute dyspnea.Is the cause cardiac or pulmonary or both?www.consultant360.com.2012;52(11).

[6]. H Kenneth Walker, W Dallas Hall, J Wallis. Cilnical Methods: The history, physical and laboratory examination. $3^{\text {rd }}$ Ed.1990;20144.

[7]. Veigi G, Paoletti P, Carozzi L. Prevalence ratesof respiratory symptoms in Italian general populatin samples exposed to different levels of air pollution. Environ Health Perspect 1991;94:95-99

[8]. Mahler DA. Measurement of dyspnea: Clinical Ratings. Mahler DA, O’Donnel DE, editors. Dyspnea. $2^{\text {nd }}$ Ed. Vol - 208. FL: Taylor and Fracis 2005; p. 147-63.

[9]. Ley R. Pulmonary Function and Dyspnea/Suffocation Theory of Panic. J BehavTherExp Psychiatry 1998 mar; $29(1): 1-11$.

[10]. Depaso WJ, Winterbauer RH, Lusk JA, Dreis DF, Springmeyer SC. Chronic dyspnea unexplained by history, physical examination, chest roentgenogram and spirometry. Analysis of a seven year experience. Chest 1991; 100: 1293-99.

[11]. Wolkove N, Dajczman E, Colacone A, Kreisman H. The relationship between pulmonary function and dyspnea in obstructive lung disease. Chest 1989;96(6):1247-51.

[12]. Delclaux C, Zerach - Lancer F, Bachir D, Habibi A, Monim JL, Gpcleau B, Galacteros F. Factors associated with dyspnea in adult patients with sickle cell disease. Chest 2005 nov; 128(5):3336-44.

[13]. Bauer TT, Heyes CM, Duchna HW, Andreas K, Weber A, Schmidt EW. Radiological Findings, Pulmonary Functions and Dyspnea in Underground Coal Miners. Int J Thor Med 2007;74(1):80-87. 